Ushus J B Mgt 15, 2 (2016), 49-55

ISSN 0975-3311| doi: 10.12725/ ujbm.35.4

\title{
HR Challenges in Big Data
}

\author{
Pala SuriyaKala* and Ravi Aditya $^{\dagger}$
}

"In God we trust, all others must bring data"-W. Edwards Deming

\begin{abstract}
Human resources is traditionally an area subject to measured changes but with Big data, data analytics, Human capital Management, Talent acquisition and performance metrics as new trends, there is bound to be a sea change in this function. This paper is conceptual and tries to introspect and outline the challenges that HRM faces in Big Data. Big Data is as one knows the world of enormous generation which is revolutionizing the world with data sets at exabytes. This has been the driving force behind how governments, companies and functions will come to perform in the decades to come. The immense amount of information if properly utilized can lead to efficiency in various fields like never before. But to do this the cloud of suspicion, fear and uncertainty regarding the use of Big Data has to be removed from those who can use it to the benefit of their respective areas of application.HR traditionally has never been very data centric in the analysis of its decisions unlike marketing, finance, etc.
\end{abstract}

\footnotetext{
* Associate Professor, Acharya Bangalore B-School, Bengaluru, India; palasuriyakala@gmail.com

${ }^{\dagger}$ Assistant Professor, Acharya Bangalore B-School, Bengaluru, India;
} 
Keywords: Human Resource Management, Big Data, HR Analytics, HCM, Performance Metrics

\section{Introduction}

Big Data: The information era and the age of digitization have ushered in an explosion of information that is immense in its proportions. Big Data is the wealth of information generated in data sets that bombard the world every second. As much as they pose a challenge, the recent times have shown that this data can be utilized to make the world a better place. The Orwellian Big Brother is akin to the Big Data that generates information about everything under the sun and can in fact benefit everything, anything and anyone if properly utilized. "Big data is a broad term for data sets so large or complex that traditional data processing applications are inadequate. Challenges include analysis, capture, curation, search, sharing, storage, transfer, visualization, and information privacy. The term often refers simply to the use of predictive analytics or other certain advanced methods to extract value from data, and seldom to a particular size of data set"1. This is a more conservative definition of Big data which looks at its functions. "Big data is a buzzword, or catchphrase, used to describe a massive volume of both structured and unstructured data that is so large that it's difficult to process using traditional database and software techniques."2

\section{Characteristics of Big Data}

Big data has a set of common characteristics which are denoted by $6 C^{\prime}$ 's and $a^{\prime} V$ '. They are as follows-

Volume - As the name Big data suggests, it is characterized by the huge size of the data. The size, value and the potential of the data available are important in characterising Big Data.

Variety - The category to which Big data belongs is variety and helps those who are closely analysing it and using it, the data analysts

\footnotetext{
1. http://en.wikipedia.org/wiki/Big_data ${ }^{2}$ www.webopedia.com/TERM/B/big_data.html
} 
Velocity - The term 'velocity' in the context refers to the speed of generation of data or how fast the data is generated and processed to meet the demands and the challenges which lie ahead in the path of growth and development.

Variability - The data tends to be variable or inconsistent which is in fact a challenge to those who are processing data

Veracity - Accuracy, validity of the data depends on the truthfulness of the data source. So the quality of the data, depends on veracity of the data source.

Complexity - As there is an immense amount of data generated, the data tends to be complex, which again poses a threat for analysts who are processing the data.

\section{Human Resources and Big Data}

Human resource Management in the past has been trying to make the functions of recruiting, appraisal, etc, more objective and has been trying to implement better statistical tools to manage its functions better. In this scenario, the inclusion of Big Data in HR will vitalise the way the functions are performed. According to a report in e-quest "With the arrival of Big Data, HR is faced with an unprecedented opportunity to become more data driven, analytical and strategic in the way that it acquires talent" 3

Further the report states that there has been a gradual movement of HR towards Big Data Style analytics. The white paper has analysed five steps that show this shift in Human resources function.

Step 1: The use of anecdotal evidence

Step 2: The use of internal data

Step 3: The use of internal Metrics

Step 4: The application of descriptive analytics

Step 5: The application of predictive Analytics.

The report implies a paradigm shift that has happened in the field of HR, when the companies have adopted Big data. Human Resources Management starts from a preliminary analysis to

${ }^{3}$ http:/ / www.equest.com/wpcontent/uploads/2013/05/equest_big_data_whitepaper_hrs_golden_opp ortunity.pdf 
predictive analysis. Therefore there is immense scope for human resources with data analytics. Phil Simon, in his book Too Big to Ignore: the Business Case for Big Data, talks about the popular perception of HR folks tending to almost exclusively rely on gut instincts versus making decisions based on data. I'm convinced that as the profession continues to embrace the use of data and analytics into its practices, that it will also continue to solidify its role within the C-Suite 4

Nick Holley, Co-Director at the Henley Centre for HR excellence in his research paper Big Data and HR5,identifies two threats that big data applications face in1) HR luddites 2) data centricity. The former explains how there can be a resistance among steadfast traditional experts to deal with big data applications in HR and also the reverse where too much data centricity with people centricity can create problems with HR managers.

\section{Objective}

The paper is conceptual in nature and has set out to study the existing data to understand the challenges lie ahead for Human Resources Management in Big data.

\section{Challenges ahead for Human resources in Big Data}

\section{To have or not to have}

Josh Bersinan authority on Human resources and big data, has conveyed that the situation for the two has been a question of have and have nots. As a result of a two year research he found that "while more than $60 \%$ of companies are now investing in Big Data and analytics tools to help make their HR departments more datadriven, there is a huge chasm between the "haves" and the "have nots." 6

${ }^{4}$ Phil Simon-Too big to ignore: the Business case for Big data

5Nick Holley, Big Data and HR- Co- Director at The Henley Centre for HR excellence- Henley Business School

6http://www.forbes.com/sites/joshbersin/2013/10/07/big-data-inhuman-resources-a-world-of-haves-and-have-nots/ 


\section{Getting the rightdata in the first place}

Getting the right data for your organizations is one of the biggest challenges of HR. Many MNC's today have access to data but the rest depend on small analytical firms that cater to the data requirement sources of a firm. Therefore sourcing the data first is great challenge for the HR firm. "Just finding the data can be a challenge, let alone integrating it and running sophisticated business-focused queries on it" 7 , says a news report

\section{Ability to use talent analytics}

Talent analytics is another area of challenge for the application of big data in HR after the acceptance by people. Talent analytics professionals are multidisciplinary professionals skilled in business understanding, consulting skills, data visualization, data management, statistics and executive presence. The analytics team have to be diagnostic problem solving and this is one of the greatest challenges.

\section{Getting people to change their behaviour}

Another biggest challenge for HR is the fact that HR Managers and Analysts find it hard to tackle or change their behaviour. The difficulty is in tackling with years of experience and setbeliefs that seasoned HR professionals hold.

\section{Opposing schools of thought}

The number ofpeople who vote for the use of Big Data are matched equally by those who oppose saying that this can have a demoralizing effect on the workers. Business ethics professor Chris MacDonald,Rogers school of Management, questions the use of statistics for decisions about people's place and success in the workplace. 'If that measurement process becomes demoralizing for staff, you've shot yourself in the foot. ${ }^{18}$

7http:/ / www.cbc.ca/news/business/big-data-trend-now-being-appliedto-managing-human-resources-1.2971266

${ }^{8}$ Dianne Buckner, CBC News Posted: Feb 26, 2015 5:00 AM ET Last Updated: Feb 26, 2015 10:13 AM ET 


\section{Skepticism on the part of the employees}

Apart from the practitioners, employees may also have a problem with the application of metrics and big data to human resources. There is a pervading feeling as a result of few surveys taken among employees; people are more than just a number as is represented in a metric.

\section{Difficulty in measuring certain Parameters}

Metrics cannot measure certain parameters, for instance enthusiasm, initiative as pointed out by the professor and explained in the following quote from a news report, speaks that fact quite explicitly. "Analytics present a raft of limitations," says Jerry Gaertner, a professor of computer science who is also the coowner of an analytics company. "What's the unit of measure for initiative? Or enthusiasm? It doesn't exist," he points out. He also says "it's next to impossible to remove bias, even by using numbers." 9

\section{Not free from Bias:}

Data that is available in the metrics can show patterns. These patterns have to be identified and interpreted. The interpretation is often done by a person, who is an analyst and anytime a person is involved one cannot assure that the interpretation is free from bias.Zang, S.Y. and Ye, M.L. (2015) in their paper "Human Resources Management in the era of Big Data, conclude that a careful use of Big Data is necessary in Human Resources." 10

\section{Conclusion}

It is undeniable that big data has an immense potential in today's world. "Big Data Is Revolutionizing the World.", "The Power of Big Data for HR.", "Top 10 Ways Big Data Is Changing Business", are the typical headlines, highlighting the way the big data has come to

${ }^{9}$ http:/ / www.cbc.ca/news/business/big-data-trend-now-being-appliedto-managing-human-resources-1.2971266

10Zang, S.Y. and Ye, M.L. (2015) Human Resource Management in the Era of Big Data. Journal of Human Resource and Sustainability Studies, 3, 4145. http://dx.doi.org/10.4236/jhrss.2015.31006 
stay and change business. It is an undeniable fact and the companies have to look first at adoption and then later the implementation of metrics. Human resources is no exception to this. Those companies who have been quick in the adoption have also been able to show considerable results, in talent acquisition, retention, etc. Therefore it is imperativethat Human Capital Management has to go hand in hand with Big Data. The Challenges are many as discussed in this paper but the benefits are far reaching and improve efficiency in the organizations like never before.

\section{References:}

Dianne Buckner, CBC News, Posted: Feb 26, 2015 5:00 AM ET Last Updated: Feb 26, 2015 10:13 AM ET

Nick Holley, Big Data and HR- Co- Director at The Henley centre for HR excellence- Henley Business School

Phil Simon.Too big to ignore: the Business case for Big data www.webopedia.com/TERM/B/big_data.html

Zang, S.Y. and Ye, M.L. (2015) Human Resource Management in the Era of Big Data. Journal of Human Resource and Sustainability Studies, 3, 41-45.

Retrieved http://dx.doi.org/ 10.4236/ jhrss.2015.31006

\section{Online References:}

http://en.wikipedia.org/wiki/Big_data

http:// www.cbc.ca/news/business/big-data-trend-now-beingapplied-to-managing-human-resources-1.2971266

http:// www.cbc.ca/news/business/big-data-trend-now-beingapplied-to-managing-human-resources-1.2971266

http://www.equest.com/wpcontent/uploads/2013/05/equest_bi g_data_whitepaper_hrs_golden_opportunity.pdf1 http://www.forbes.com/sites/joshbersin/2013/10/07/ big-datain-human-resources-a-world-of-haves-and-have-nots / 